\title{
Políticas públicas educacionais e formação de professores: convergências e distanciamentos na área de Educação Especial
}

Public educational policies and teacher training: convergences and divergences in the Special Education area

Políticas públicas educativas y formación de profesores: Convergencias y distanciamientos en la Educación Especial

\section{Bruno Cleiton Macedo do Carmo}

Doutorando na Universidade Federal de Alagoas, Maceió, Alagoas, Brasil.

bruno.cleiton.macedo@gmail.com

ORCID - https://orcid.org/0000-0002-6569-1653

Neiza de Lourdes Frederico Fumes

Professora titular na Universidade Federal de Alagoas, Maceió, Alagoas, Brasil.

neizaf@yahoo.com

ORCID - https://orcid.org/0000-0002-1913-4784

\section{Elisangela Leal de Oliveira Mercado}

Professora doutora na Universidade Federal de Alagoas, Maceió, Alagoas, Brasil.

elisangela.mercado@cedu.ufal.br

ORCID - https://orcid.org/0000-0003-2815-4813

\section{Luciana de Oliveira Rocha Magalhães}

Doutoranda na Pontifícia Universidade Católica de São Paulo, São Paulo, São Paulo, Brasil.

lucianam11@hotmail.com

ORCID - https://orcid.org/0000-0002-7677-6337

Recebido em 23 de julho 2018

Aprovado em 11 de novembro de 2019

Publicado em 12 de dezembro de 2019

\section{RESUMO}

As políticas educacionais caminharam desde as últimas décadas do século XX em direção ao paradigma da inclusão escolar, demandando novas práticas docentes, como recorrentes estudos da área demonstram, e consequentemente exigem repensar a formação de professores. Assim, o objetivo do presente artigo é analisar as políticas públicas educacionais e as de formação de professores no intuito de refletir sobre possíveis convergências e distanciamentos na construção de um sistema de ensino capaz de atender à diversidade trazida pela inclusão escolar. Para tanto, foram analisadas as principais legislações e ações governamentais de 1994 a 2018. Os dados foram coletados em sítios oficiais do Governo Federal, no Diário Oficial da União e através de revisão bibliográfica. Reconhecendo que um único pesquisador não é capaz de esgotar a revisão das políticas públicas e as produções científicas elaboradas sobre a temática, optou-se pela conferência dos dados por 3 especialistas na área de Educação Especial e formação 
http://dx.doi.org/10.5902/1984686X39223

de professores, visando uma maior confiabilidade dos dados apresentados. A partir dos resultados alcançados, percebe-se que as políticas públicas educacionais de inclusão e de formação de professores, ao longo das últimas décadas, convergiram no sentido de assumir o paradigma da inclusão como norte para os sistemas de ensino no Brasil. Contudo, parece haver um descompasso entre as ações governamentais para a inclusão de alunos público-alvo da Educação Especial e a formação de professores para atendêlos, ficando esta última como uma preocupação secundária nas políticas públicas para a inclusão escolar.

Palavras-chave: Inclusão educacional; Política da educação; Formação de professores.

\section{ABSTRACT}

Education policies have progressed in the last two decades of the twentieth century in the field of school inclusion; however recurrent studies have shown that the teaching practice has undergone profound changes to act in this recent scenario in educational institutions, which it requires rethinking the teacher formation. The present article aims to analyze the public educational policies and teacher formation in order to reflect about convergences and distances in construction an education system to attend the diversity imposed by school inclusion. Thus, the main legislation and government actions from 1994 to 2018 were analyzed. The data were collected on official government websites, on official journal of the federal government of Brazil and through the bibliographic review. Recognizing that a single researcher is not able to exhaust the revision of the public policies and scientific productions elaborated about the subject, it was decided to conference the data by 3 specialists in Special Education and teacher formation aiming to ensure greater reliability and consistency of data stored. Based on the results achieved, it can be seen over the last decades that public educational policies of inclusion and teacher formation have converged to assume the paradigm of inclusion as a key point to education systems in Brazil. However, there seems to be a mismatch between government actions for students that need of Special Education and the teacher formation to attend them, being the teacher formation a secondary concern in public policies for school inclusion.

Keywords: Educational inclusion; Education policy; Teacher formation.

\section{RESUMEN}

Las políticas educativas han progresado en las últimas dos décadas del siglo veinte en el campo de la inclusión escolar; sin embargo, estudios recurrentes han demostrado que la práctica docente ha sufrido cambios profundos para actuar en este escenario reciente en las instituciones educativas. El presente artículo tiene como objetivo analizar las políticas educativas públicas y la formación docente para reflexionar sobre las convergencias y las distancias en la construcción de un sistema educativo para atender la diversidad impuesta por la inclusión escolar. Así, se analizaron las principales medidas legislativas y gubernamentales de 1994 a 2018. Los datos fueron recolectados en los sitios web oficiales del gobierno, en el diario oficial del gobierno federal de Brasil y a través de revisión bibliográfica. Reconociendo que un solo investigador no puede agotar la revisión de las políticas públicas y las producciones científicas elaboradas sobre el tema, se decidió realizar una conferencia de los datos por 3 especialistas en educación especial con el objetivo de garantizar una mayor confiabilidad de los datos. De los resultados obtenidos se puede ver en las últimas décadas que las políticas públicas de inclusión y formación docente han convergido para asumir el paradigma de la inclusión como un punto clave para los sistemas educativos en Brasil. Sin embargo, parece haber un desajuste entre las acciones gubernamentales para los estudiantes que necesitan educación especial y la formación de 
maestros para asistir a ellos, siendo la formación de maestros una preocupación secundaria en las políticas públicas para la inclusión escolar.

Palabras clave: Inclusión educativa; Política educativa; Formación de profesores.

\section{Introdução}

Conceituar política pública não é das tarefas mais fáceis, tamanha a variedade de conceitos que se encontra na literatura. Porém, as políticas públicas constituem um conjunto de atividades dos governos que influenciam direta ou indiretamente a vida das pessoas sobre sua governança. Para Souza (2006), política pública se constitui num campo do conhecimento que busca colocar em prática ações governamentais, analisar essas ações e propor mudanças, quando necessárias. Nos Estados democráticos, a formulação de políticas públicas, tradicionalmente muito atrelada aos poderes executivo e legislativo, cada vez mais, sofre influência do poder judiciário, sociedade civil organizada e do mercado de capital. Contudo, mais especificamente na América Latina, a falta de coalizões políticas tem tornado os governos incapazes de promover políticas públicas apropriadas para fomentar o desenvolvimento econômico e, ao mesmo tempo, promover a inclusão social (SOUZA, 2006).

Em relação à educação, a agenda das políticas públicas vem se constituindo de um espaço de disputas entre diversos setores para a definição dos seus rumos e objetivos (OLIVEIRA, 2014; LIBÂNIO; OLIVEIRA; TOSCHI, 2012). Novos contextos sociais, políticos e econômicos, aliados a agentes internacionais, denotam que as políticas educacionais não podem ser compreendidas se analisadas de maneira isoladas, pois elas resultam da inter-relação entre diversos aspectos e atores (BALL; MAINARDES, 2011; AMARAL, 2010). Silva (2016) destaca, por exemplo, que as definições das políticas educacionais pela oferta do ensino técnico na década de 1970 e do ensino elementar nas décadas de 1980 e 1990 foram direcionadas pelo Banco Mundial através de ações para a educação que ocorriam em forma de empréstimos financeiros ao governo brasileiro. Todavia, a qualidade dessas políticas era e ainda é questionável, uma vez que esses organismos internacionais defendem a apropriação de conteúdos mínimos, principalmente, língua portuguesa e matemática, os ditos básicos.

A contestação da qualidade da educação ofertada pelo poder público, que perdura até a atualidade, fomenta as políticas públicas de avaliação; o que segundo Oliveira (2014) retira o foco sobre o direito à educação e o direciona para racionalidade 
http://dx.doi.org/10.5902/1984686X39223

administrativa que na busca de resultados, termina por perder a concepção da educação como um bem público e um direito social. Porém, desde a década de 1990, a inclusão de pessoas excluídas dos processos educacionais vem ganhando destaque e políticas públicas estão sendo requeridas a fim de tornar os sistemas de ensino mais preparados e abertos para atender à diversidade no ambiente escolar.

Oliveira (2014) destaca que a concepção de educação para todos surge como resposta aos sistemas organizados em padrões universais, os quais terminam por excluir os que não respondem a certos critérios de normalidade. Foi diante desse novo paradigma, a inclusão, que as políticas públicas passaram a contemplar diversos grupos que, por motivo de classe social, idade, gênero ou deficiência, foram historicamente excluídos dos processos educacionais. O Ingresso desse público no sistema regular de ensino intensificou os questionamentos em relação à qualidade do serviço prestado, pois as práticas educativas tradicionais já não apresentavam, minimamente, resultados satisfatórios diante do novo cenário vivenciado pelas instituições de ensino.

Tardif (2014) defende que, com a escolarização de massa em todos os níveis do sistema de ensino, exige-se cada vez mais, dos professores, a capacidade de lidar com inúmeros desafios em suas ações pedagógicas. Isso fomenta a necessidade de repensar a formação docente, a qual deve levar em consideração os saberes dos professores e as realidades específicas de seu trabalho cotidiano. Apesar disso, a formação de professores para atuar na Educação Especial continua em aberto, embora tenha ganhado importância nas últimas décadas (SAVIANI, 2009).

Os modelos de formação dos profissionais do magistério, assumidos até o momento, visando qualificar para o trabalho no novo cenário da educação brasileira, parecem perpetuar o conhecimento hegemônico na Educação Especial, o qual está vinculado à carência de debate pedagógico e de discussões sobre o trabalho do professor (GARCIA, 2013).

Diversos pesquisadores da área de Educação Especial vêm apontando barreiras que dificultam o trabalho docente nas instituições de ensino, que vão desde a carência de condições apropriadas de trabalho aos problemas de ordem mais geral, como no campo da cultura e de conhecimentos específicos do processo de ensino-aprendizagem. Todavia, todos apontam na direção de falhas no processo de formação, desde a inicial à continuada, passando por problemas na legislação que regula essas formações (MENDES, 2019; LAPLANE 2015; GREGUOL; GOBBI; CARRARO, 2013; KUHN, 2011). 
http://dx.doi.org/10.5902/1984686X39223

Assim, o objetivo do presente artigo é analisar as políticas públicas de inclusão escolar e as de formação de professores para a inclusão nas instituições de ensino regular e refletir sobre suas possíveis convergências e distanciamentos.

\section{Método}

Este estudo integra um projeto de tese de doutorado em educação que tem por objetivo investigar o impacto das políticas públicas de inclusão escolar na formação de professores para o atendimento na educação básica da rede regular de ensino.

Para o presente estudo, optou-se por uma pesquisa documental que segundo SáSilva, Almeida e Guindani (2009), possibilita conhecer objetos estudados, permitindo uma melhor compreensão da sua realidade. Partindo de questões de interesse, esse método de pesquisa ao fazer uso de técnicas apropriadas e procedimentos sistematizados, viabiliza a extração de informações de documentos que ainda não foram analisados em relação ao tema proposto.

Os documentos analisados foram normativos provenientes do poder executivo e legislativo federal, tais como: leis, decretos, resoluções, portarias e notas técnicas, programas e projetos do governo federal; além de documentos internacionais ratificados pelo governo brasileiro. Todos eles versando sobre a inclusão de pessoas com deficiência entre os anos de 1994 e 2018.

A coleta de dados foi realizada em sítios oficiais do governo federal, como o portal do Ministério da Educação e sítio do congresso federal; também foram coletados dados no sítio do Diário Oficial da União. A leitura da produção bibliográfica da área, também serviu de ponto de partida para a busca dos documentos oficiais do período estudado.

Após essa fase de coleta de dados, os mesmos foram sistematizados em um quadro em que continha: a) o ano da política pública; b) a descrição do tipo de política (se lei, decreto, programa, projeto ou outros); c) os reflexos em relação à educação inclusiva e d) os reflexos na formação dos professores para a educação inclusiva. Entendendo-se a complexidade do tema abordado e o longo período estudado, o quadro com os dados foi submetido à conferência de três pesquisadores especializados na área de Educação Especial e formação de professores, os quais verificaram a pertinência dos dados e se faltava algum documento essencial que tratasse da temática. Esse procedimento visou proporcionar uma maior confiabilidade dos dados obtidos. Após a devolutiva dos pesquisadores, um novo quadro foi formado e utilizado para análise. Ao todo foram 
http://dx.doi.org/10.5902/1984686X39223

incluídos na análise 46 documentos elaborados entre os anos de 1994 e 2018, destes, 13 foram decretos do poder executivo ou legislativo, 7 leis, 7 portarias, 6 notas técnicas, 5 documentos internacionais, 5 resoluções e 3 projetos/programas do governo federal.

Para a análise dos documentos, foi utilizada a técnica de análise de conteúdo proposta por Bardin (2004). Em um primeiro momento, foi realizada uma leitura exaustiva e pormenorizada dos documentos encontrados na qual se procurou extrair as ideias centrais contidas nos normativos, assim como distanciamentos e convergências entre os reflexos esperados na inclusão de alunos com deficiência e a formação de professores para atender os mesmos. Após essa fase, cada documento passou pela demarcação e identificação de unidades temáticas que correspondem à identificação dos termos objeto do estudo, levando à criação de categorias de análises. Uma pré-análise foi realizada nas categorias identificadas e, quando foi necessário, novas categorias foram demarcadas. Esse processo ocorreu até a saturação do procedimento de identificação de novas categorias e, então, foram fixadas as categorias definitivas do estudo.

\section{Resultados e Discussão}

O resultado da categorização das unidades temáticas indicou 3 categorias de análises: a) a influência externa nas políticas públicas de educação inclusiva; b) o acesso dos alunos com deficiência como o norte das políticas públicas de inclusão; c) a secundarização da formação de professores para o atendimento de alunos com deficiência e os diferentes modelos adotados no Brasil.

\section{A influência externa nas políticas públicas de educação inclusiva}

Saindo de um período de crise econômica que perdurou toda a década de 1980 e início dos anos 1990, o Brasil de 1994 encontrava-se dependente de empréstimos financeiros, principalmente os provenientes do Banco Mundial e do Fundo Monetário Internacional. Nessa conjuntura, algumas condições foram impostas ao país por esses organismos internacionais e uma delas dizia respeito a mudanças na educação básica as quais deveriam reverter os altos índices de analfabetismos e universalizar o ensino básico para todos. Essas demandas se alinham a uma perspectiva do mercado de trabalho que requer uma mão-de-obra melhor qualificada para lidar com as novas tecnologias que passaram a surgir na época (MOTA JÚNIOR; MAUÉS, 2014) 
http://dx.doi.org/10.5902/1984686X39223

Em relação à Educação Especial, no ano de 1994 é realizada a Conferência Mundial de Educação Especial onde o Brasil, juntamente com outros países, assumiu o compromisso de prover a educação de todos os alunos independente das suas condições, eliminando barreiras para que os alunos com deficiência, pudessem ingressar no ensino regular. Promovida pela UNESCO, na Espanha, a conferência resultou na elaboração do documento denominado Declaração de Salamanca que passou a nortear, a partir de então, as políticas públicas de inclusão da educação brasileira (UNESCO, 1994).

Apesar de já constar em alguns dispositivos legais, entre eles, a Constituição Federal de 1988 (art. 208, III), é através da Declaração de Salamanca que a inclusão de alunos com deficiência no ensino regular ganha força, pois ela reforça que a escola regular é o melhor local para que a educação desses alunos ocorra, além de que o ensino regular apresenta custos menores para o sistema educacional quando comparado às instituições especializadas (UNESCO, 1994; BRASIL, 1988).

Ciente de que uma educação inclusiva necessita de professores bem qualificados para lidar com os alunos com deficiência que passariam a frequentar as escolas regulares, a Declaração de Salamanca destaca que a formação de professores deve constituir-se em um dos principais pontos das políticas públicas nacionais de inclusão: "Preparação apropriada de todos os educadores constitui-se um fator chave na promoção de progresso no sentido do estabelecimento de escolas inclusivas" (UNESCO, 1994, s/p), Além disso conclama que mudanças nos currículos dos cursos de formação de professores devem ser feitas no sentido de que os futuros profissionais assumam uma postura positiva frente à deficiência e que formação em serviço seja uma constante para aqueles que já estão nas escolas (UNESCO, 1994).

Outro documento internacional que influenciou as políticas públicas de inclusão adotadas pelo Brasil foi o que resultou da Convenção Interamericana para a Eliminação de Todas as Formas de Discriminação contra as Pessoas Portadoras de Deficiência realizada em 1999. A Convenção de Guatemala, como ficou conhecida, foi incorporada ao ordenamento brasileiro através do Decreto 3.956/2001 e traz consigo medidas para o enfrentamento de qualquer tipo de discriminação e que facilitem o acesso de pessoas com deficiência nas mais variadas instâncias e instrumentos públicos, entre eles, os educacionais. Contudo, não há menção aos profissionais da educação ou a formação de professores no texto (BRASIL, 2001). 
http://dx.doi.org/10.5902/1984686X39223

A Convenção de Guatemala é um dos pilares de várias outras leis, decretos, portarias e programas do governo brasileiro que promoveram, principalmente nos anos 2000, uma completa mudança no cenário da educação dos alunos com deficiência com estes passando a frequentar majoritariamente as instituições regulares de ensino.

A Declaração Internacional de Montreal sobre Inclusão, outro documento internacional que o Brasil é signatário, destaca a importância de que os princípios do desenho inclusivo sejam incorporados nos currículos de todos os programas de educação e treinamento. Apesar de não fazer referência direta à formação de professores, este documento também serviu para fomentar mudanças nos cursos de formação docente, uma vez que, em anos posteriores, a inserção de conteúdos sobre o tema da inclusão nos currículos das licenciaturas se consolidou como o pilar de sustentação das políticas públicas de formação inicial de professores para preparar os mesmos para o atendimento de pessoas com deficiência no ensino regular (CONGRESSO INTERNACIONAL SOCIEDADE INCLUSIVA, 2001).

Contudo, apenas com a Convenção da Organização das Nações Unidas sobre os Direitos das Pessoas com Deficiência, realizada em 2006 é que a formação de professores surge de maneira mais direta e efetiva como norteador de garantia de um sistema educacional verdadeiramente inclusivo. Assim são destaques no texto fruto da convenção a exigência de qualificação adequada e de professores especializados para atuarem com pessoas com deficiência em todos os níveis de ensino:

Art. 24, item 4 - A fim de contribuir para o exercício desse direito [direito à educação], os Estados Partes tomarão medidas apropriadas para empregar professores, inclusive professores com deficiência, habilitados para o ensino da língua de sinais e/ou do Braille, e para capacitar profissionais e equipes atuantes em todos os níveis de ensino. Essa capacitação incorporará a conscientização da deficiência e a utilização de modos, meios e formatos apropriados de comunicação aumentativa e alternativa, e técnicas e materiais pedagógicos, como apoios para pessoas com deficiência. (ONU, 2007)

O texto da Convenção da ONU sobre os Direitos das Pessoas com Deficiência foi incorporado ao ordenamento brasileiro pelo Decreto Legislativo ํo 186/2008 e, posteriormente, pelo Decreto Presidencial № 6.949/2009 (BRASIL, 2009; BRASIL, 2008a).

$O$ fato da internacionalização das políticas públicas educacionais interferirem nas tomadas de decisões internas adotadas pelo Brasil é um ponto importante ao se analisar os rumos que as políticas públicas tomaram no país para promover a inclusão das pessoas com deficiência, inclusive quanto aos investimentos financeiros (PANSINI, 2018; 
http://dx.doi.org/10.5902/1984686X39223

AKKARI, 2011). Todos os documentos internacionais, de maneira muito direta e incisiva, direcionam esforços no sentido de possibilitar o acesso ao direito à educação, porém a formação docente aparece apenas em alguns documentos e em segundo plano não apresentando, na maioria das vezes, medidas concretas que devem ser adotadas pelos países afim de assegurar a formação para os professores que irão receber esses alunos no ensino regular.

Nesse cenário, Akkari (2011) afirma que não se pode conceber e implementar políticas nacionais de educação sem considerar os debates internacionais e que o poder de regulação dos Estados depende de sua posição no crescente cenário de internacionalização e globalização. Assim, o Banco Mundial classificou o sistema educacional brasileiro, junto ao de outros países da América Latina, Ásia e Norte da África como sistema emergente, no qual a taxa de escolarização é alta. Porém, alguns setores da população ainda enfrentam serviços educacionais de baixa qualidade, nesse cenário $o$ setor privado é favorecido (BANCO MUNDIAL, 1999).

Além dos fatores externos, as políticas públicas educacionais estão tensionadas por forças internas, como o interesse e as necessidades de grupos políticos, instituições privadas e associações de pais e trabalhadores da educação (AKKARI, 2011). Em um país como o Brasil, com grande extensão territorial e diferenças regionais, isso pode configurar-se em um obstáculo no desenvolvimento da educação à medida que se desvia esforços e investimentos para atender a interesses de algum grupo específico, deixando os mesmos de ser direcionados para o sistema educacional como um todo, principalmente no que se refere a uma política educacional mais ampla e que busca resultados em longo prazo.

\section{O acesso dos alunos com deficiência como o norte das políticas públicas de inclusão}

A exclusão de pessoas com deficiência vem sendo mitigada em várias esferas e no âmbito educacional isso se tornou mais evidente a partir dos anos 1990 quando políticas públicas passam a ser elaboradas tendo como foco principal a inserção dessas pessoas no sistema educacional. Dos 46 documentos analisados, 30 tratavam, de maneira direta ou indireta, do acesso dos alunos com deficiência no sistema de ensino regular.

Algumas frentes de ações estão bem destacadas nos textos, como as adequações arquitetônicas de equipamentos educacionais; regras de financiamento para prover os 
http://dx.doi.org/10.5902/1984686X39223

custos operacionais da entrada desses alunos no sistema de ensino; universalização do acesso à educação; ampliação do uso da LIBRAS nas instituições educacionais; e adoção da estratégia do Atendimento Educacional Especializado (AEE) como suporte para melhorar o aprendizado dos alunos público-alvo da Educação Especial.

As políticas de acessibilidade, mesmo quando não realizadas especificamente para o espaço educacional, refletem nas instituições de ensino uma vez que estas se caracterizam como equipamentos de uso coletivo, como pode ser percebido nos trechos destacados das leis no $10.098 / 2000$ e $n^{0}$ 13.146/2015:

A construção, ampliação ou reforma de edifícios públicos ou privados destinados ao uso coletivo deverão ser executadas de modo que sejam ou se tornem acessíveis às pessoas portadoras de deficiência ou com mobilidade reduzida (BRASIL, 2000, Lei no 10.098/2000, art. 11)

Art. 28. Incumbe ao poder público assegurar, criar, desenvolver, implementar, incentivar, acompanhar e avaliar:

I - Sistema educacional inclusivo em todos os níveis e modalidades, bem como o aprendizado ao longo de toda a vida;

II - Aprimoramento dos sistemas educacionais, visando a garantir condições de acesso, permanência, participação e aprendizagem, por meio da oferta de serviços e de recursos de acessibilidade que eliminem as barreiras e promovam a inclusão plena [...] (BRASIL, 2015, Lei no 13.146/2015)

Contudo, sem dúvidas, a política pública mais enfática em relação à acessibilidade nas instituições de ensino adotada até agora ocorreu a partir do Programa Escola Acessível, instituído em 2007, no escopo do Plano de Desenvolvimento da Educação PDE (BRASIL, 2007a). Anteriormente, o Ministério da Educação apoiava projetos de adequações arquitetônicas propostos pelas secretarias estaduais e municipais de educação e que fossem aprovados pela Secretaria de Educação Especial, sob sua alçada. Esse mecanismo perdurou até 2006, findando com a implantação do Programa Escola Acessível.

Regularizado pela Resolução no 26/2007, do Conselho Deliberativo do Fundo Nacional de Desenvolvimento da Educação (CD/FNDE), o repasse de recursos financeiros para a adequação das estruturas físicas de escolas tornou-se mais sistematizado. Porém, apenas no ano seguinte, 2008, o processo de transferência de recursos para a acessibilidade passou a ser realizado diretamente para as unidades executoras das escolas. Ao longo dos anos, o Programa Escola Acessível foi sofrendo ajustes e modificações condicionando 0 repasse financeiro às instituições que apresentassem Salas de Recursos Multifuncionais e com matrículas de estudantes público-alvo da Educação Especial registradas no Censo Escolar do INEP (FNDE, 2007). 
http://dx.doi.org/10.5902/1984686X39223

Na última modificação promovida através da Resolução nํㅜ 20, de 19 de outubro de 2018, do CD/FNDE, os repasses dos recursos financeiros passam a ocorrer nos moldes do Programa Dinheiro Direto na Escola, na proporção de 80\% para cobertura de despesas de custeio e 20\% para cobertura de despesas de capital. Levando-se em consideração o número de alunos matriculados na escola, os valores destinados às adequações de acessibilidade variam entre $R \$$ 9.960,00 para as unidades com até 199 alunos, chegando a $\mathrm{R} \$ 18.000,00$ nas unidades que tenham acima de 1.000 alunos registrados no Censo Escolar (FNDE, 2018).

Apesar de ser uma política pública mais contundente para promover o acesso à educação de alunos com deficiência, alguns problemas ainda fragilizam os resultados que poderiam ser alcançados como a extensa burocracia para que as secretarias estaduais e municipais de educação e escolas possam atender os requisitos solicitados a fim de serem contempladas pelo programa; a demora na liberação dos recursos financeiros quando contempladas; os valores relativamente baixos para custear as ações que o programa propõe; mudanças políticas e organizacionais a exemplo da extinção da Secretaria de Educação Continuada, Alfabetização, Diversidade e Inclusão (SECADI), responsável pelo Programa Escola Acessível e os recentes cortes nos recursos destinados à educação que podem comprometer a efetividade dos repasses financeiros. Esses dois últimos obstáculos foram impostos pelo atual governo do presidente Jair Bolsonaro, através do Decreto № 9.465/2019 e do Decreto no 9.741/2019, respectivamente (BRASIL, 2019a; BRASIL, 2019b).

Outro mecanismo utilizado para garantir o acesso à educação de pessoas com deficiência foi a adoção de políticas públicas visando mudanças nas regras de financiamento e assistência social direcionadas aos estudantes público-alvo da Educação Especial, a exemplo da Portaria Interministerial no 18, de 24 de abril de 2007, que instituiu o Programa de Acompanhamento e Monitoramento do Acesso e Permanência na Escola das Pessoas com Deficiência Beneficiárias do Benefício de Prestação Continuada da Assistência Social - Programa BPC na Escola (BRASIL, 2007b).

Um dos objetivos do Programa BPC na Escola é a identificação de barreiras que se constituem em obstáculos para o acesso ou a permanência de estudantes com deficiência nas instituições de ensino. A identificação dessas barreiras se dá através da aplicação de questionários aos beneficiários do BPC, além disso é realizada a identificação anual das pessoas com deficiência que são beneficiárias do BPC/LOAS e sua condição de matrícula 
http://dx.doi.org/10.5902/1984686X39223

no sistema regular de ensino, através do cruzamento de dados do sistema DATAPREV do Ministério da Cidadania com os dados do Censo Escolar, realizado pelo INEP, órgão vinculado ao Ministério da Educação (BRASIL, 2007b).

No primeiro cruzamento de dados do DATAPREV com o Censo Escolar, realizado em 2007, verificou-se que dos 340.536 beneficiários do BPC destinados a pessoas com deficiência entre zero e dezoito anos de idade apenas 29,53\% estavam matriculadas no sistema regular de ensino; os outros $70,47 \%$ dos beneficiários não possuíam nenhum registro nos dados do Censo Escolar (CAIADO et al., 2014). Cabe destacar que as pessoas com deficiência beneficiárias do BPC são aquelas que tendem a apresentar maior comprometimento motor, sensorial ou cognitivo. Sendo uma ação interministerial o Programa BPC na Escola articula ações entre vários setores da administração pública, buscando otimizar o acesso dos alunos com deficiência às instituições de ensino:

Art. $3^{\circ}$ Instituir mecanismos de apoio técnico e financeiro aos Sistemas de Ensino e aos órgãos que compõem os Sistemas Único de Assistência Social - SUAS e de Saúde - SUS, para a oferta de recursos, serviços e atendimento educacional especializado complementar ou suplementar à escolarização, bem como outros recursos e serviços que favoreçam o acesso e a permanência das pessoas com deficiência beneficiárias do BPC/LOAS no sistema de ensino (BRASIL, 2007b, Portaria Interministerial no 18 , de 24 de abril de 2007).

A articulação entre setores, como Educação, Saúde e Serviço Social parece ser uma boa estratégia para facilitar o acesso de alunos com deficiência à educação, principalmente dos alunos mais vulneráveis, seja pela sua situação de deficiência ou por sua situação econômica (CUNHA, 2015). Contudo, ações como essas ficam a cargo de vontades políticas, livre adesão dos municípios brasileiros, e disponibilidade de recursos financeiros. Mesmo assim, os resultados dessa política de acesso parecem ser promissores em relação ao aumento do número de matrículas (CAIADO et al., 2014).

Todavia, a política pública mais significativa e polêmica, em relação ao aporte financeiro para custear o acesso de alunos com deficiência nas instituições de ensino, sem dúvidas, foi o cômputo duplo de matrículas, no âmbito do FUNDEB, disposto nos Decretos nํ 6.571/2008 e no seu sucessor o Decreto nำ 7.611/2011:

Art. 6ㅇ Decreto no 6.253, de 13 de novembro de 2007, passa a vigorar acrescido do seguinte artigo:

"Art. 9-A. Admitir-se-á, a partir de 10 de janeiro de 2010, para efeito da distribuição dos recursos do FUNDEB, o cômputo das matrículas dos alunos da educação regular da rede pública que recebem atendimento educacional especializado, sem prejuízo do cômputo dessas matrículas na educação básica regular. (BRASIL, 2008b, Decreto no 6.571/2008) 
http://dx.doi.org/10.5902/1984686X39223

Art. 8을 Decreto $n^{\circ}$ 6.253, de 2007, passa a vigorar com as seguintes alterações:

'Art. 9०-A. Para efeito da distribuição dos recursos do FUNDEB, será admitida a dupla matrícula dos estudantes da educação regular da rede pública que recebem atendimento educacional especializado.

$\S 1^{\circ}$ A dupla matrícula implica o cômputo do estudante tanto na educação regular da rede pública, quanto no atendimento educacional especializado.

$\S 2^{\circ} \mathrm{O}$ atendimento educacional especializado aos estudantes da rede pública de ensino regular poderá ser oferecido pelos sistemas públicos de ensino ou por instituições comunitárias, confessionais ou filantrópicas sem fins lucrativos, com atuação exclusiva na educação especial, conveniadas com o Poder Executivo competente, sem prejuízo do disposto no art. 14.'

'Art. 14. Admitir-se-á, para efeito da distribuição dos recursos do FUNDEB, o cômputo das matrículas efetivadas na educação especial oferecida por instituições comunitárias, confessionais ou filantrópicas sem fins lucrativos, com atuação exclusiva na educação especial, conveniadas com o Poder Executivo competente.

$\S 1^{\circ}$ Serão consideradas, para a educação especial, as matrículas na rede regular de ensino, em classes comuns ou em classes especiais de escolas regulares, e em escolas especiais ou especializadas.

$\S 2^{\circ} \mathrm{O}$ credenciamento perante o órgão competente do sistema de ensino, na forma do art. 10, inciso IV e parágrafo único, e art. 11, inciso IV, da Lei no 9.394, de 1996, depende de aprovação de projeto pedagógico.' (BRASIL, 2011, Decreto ํㅜ 7.611/2011)

O Decreto 6.571/2008 possibilitou a implantação do Atendimento Educacional Especializado - AEE nas redes municipais e estaduais de ensino, na medida em que implementou o duplo financiamento pelo FUNDEB aos estudantes matriculados simultaneamente na escolar regular e no AEE, ou seja, pelos alunos da Educação Especial que recebem o AEE é destinado a instituição o valor dobrado para o custeio de suas despesas. O mesmo decreto impusera que o financiamento da matrícula no AEE fosse condicionado à matrícula no ensino regular da rede pública, com base nos registros do Censo Escolar do ano anterior.

Esse novo cenário de destinação de recursos financeiros para a Educação Especial enfraqueceu as instituições que mantinham escolas especiais que até então recebiam, quase que exclusivamente, os recursos destinados à educação de pessoas com deficiência (MANTOAN, 2018). É nesse cenário que a Educação Especial se reconfigura e adota definitivamente como modelo de atendimento o AEE.

Contudo, ambos os decretos que regulamentam o duplo cômputo de matrícula possibilitam que as matrículas de alunos com deficiência também sejam realizadas em classes especiais de escolas regulares ou especializadas, incluindo as instituições comunitárias, confessionais ou filantrópicas sem fins lucrativos desde que estas sejam conveniadas ao poder executivo competente, no caso, estados ou municípios. Essa abertura permite que as instituições privadas continuem recebendo recursos públicos 
http://dx.doi.org/10.5902/1984686X39223

destinados à Educação Especial, uma vez que elas exercem grande influência sobre os parlamentares, gestores do executivo e opinião pública para a manutenção do financiamento, através de convênios com o Poder Público, para a prestação de serviços da Educação Especial (FRANÇA; PRIETO, 2018; FRANÇA, 2015).

Todas essas políticas públicas de acesso e financiamento da Educação Especial promoveram a consolidação de uma mudança radical nas instituições da rede regular de ensino que passaram a ser o locus, principal da política de educação Inclusiva no país. 0 número de alunos com deficiência nessas instituições aumentou consideravelmente e a preocupação, passou a ser, além do acesso, a permanência e a qualidade dos serviços educacionais prestados a essa população. Nesse sentido, a lei no 13.005/2014 aprovou o Plano Nacional de Educação que tem como uma das metas universalizar para a população público-alvo da Educação Especial, na faixa etária de 4 a 17 anos, além do acesso à educação básica e ao AEE, a garantia de um sistema educacional inclusivo (BRASIL, 2014).

Caiado et al. (2014) postulam que ainda há muito o que ser feito para que o sistema educacional seja realmente efetivo e inclusivo, garantindo a apropriação do conhecimento escolar pelos alunos com deficiência. As mesmas autoras apontam ainda que a valorização e formação dos professores são questões fundamentais para se alcançar tais objetivos.

\section{A secundarização da formação de professores para o atendimento de alunos com deficiência e os diferentes modelos adotados no Brasil}

A formação de uma agenda de políticas públicas leva em consideração vários elementos, como a vontade política, o feedback da sociedade em relação às ações governamentais que serão implementadas, além de questões orçamentárias (CARVALHO, 2017). Rocha (2011) postula que na área educacional a agenda de políticas públicas foi pautada, no final do século $\mathrm{XX}$, sobre a necessidade de reforma das instituições de ensino. Assim, sindicatos, universidades, empresários e instituições financeiras internacionais exerceram forte lobby na determinação das ações prioritárias que foram adotadas pelo governo. Contudo, apesar dos diferentes interesses, o consenso em torno da valorização e da importância da educação foi criado entre os diferentes atores envolvidos, sejam aqueles defensores da economia de mercado, sejam aqueles que pensavam a educação como meio de formação política e cultural do cidadão. 
http://dx.doi.org/10.5902/1984686X39223

Nesse contexto, a universalização da educação ganhou força e junto a ela a defesa de que pessoas com deficiência não poderiam ser excluídas do processo educacional. Dados dos censos escolares demonstram que o número de alunos matriculados na Educação Especial que frequentavam o ensino regular em classes comuns saltou de 81.695 no ano 2000 para $1.014 .611 \mathrm{em} 2018$, um aumento de aproximadamente $1.142 \%$, apenas nas primeiras décadas do século XXI (INEP, 2001; INEP 2019).

Esse e outros fatos, fizeram com que a profissão docente passasse por profundas transformações, bem como as exigências para a sua formação. Não obstante, Libânio, Oliveira e Toschi (2012) destacam que, apesar das reformas educacionais passarem a exigir dos professores uma ampliação das suas tarefas e que eles apresentassem resultados positivos, pouco ou quase nada lhes foi oferecido em troca.

No campo da educação da pessoa com deficiência, um dos caminhos mais eficazes para o sucesso da inclusão escolar é a formação de professores, que parece relegada a um segundo plano nas políticas públicas. Dos documentos analisados, 40\% não fazem qualquer referência à formação docente. Esse fato corrobora a ideia de que o processo de inclusão escolar no Brasil foi pensado de maneira fragmentada em que, em um primeiro momento, a preocupação foi apenas a inserção dos alunos com deficiência nas instituições de ensino, sem a observância de critérios mínimos de garantia de qualidade, como a preparação dos docentes que os receberiam.

Akkari (2011) informa que há complexas implicações envolvidas no processo de formação de professores, pois os docentes constituem a classe de trabalhadores numericamente mais importante, o que impõe um custo econômico e político sobre qualquer medida adotada que afete diretamente esses profissionais. Seguindo a tendência internacional em relação à formação de professores, o Brasil, nos anos 2000, adota o que Akkari (2011) denomina de universitarização da formação, passando essa a ser realizada, quase que exclusivamente, por instituições de ensino superior (AKKARI, 2011; SAVIANI, 2009).

Recursos financeiros foram destinados para fomentar a formação docente, tendo sido criados o Fundo de Manutenção e Desenvolvimento do Ensino Fundamental e de Valorização do Magistério (FUNDEF) e, posteriormente, a sua substituição pelo Fundo de Manutenção e Desenvolvimento da Educação Básica e de Valorização dos Profissionais da Educação (FUNDEB), além de programas como Pró-licenciatura, Pró-letramento, PróFormação, Rede Nacional de Formação Continuada de Professores e a ampliação de 
http://dx.doi.org/10.5902/1984686X39223

vagas nos cursos superiores de licenciatura em instituições públicas e privadas. Todas essas ações tinham como intuito melhorar a formação docente. Todavia, apesar de ter ganho força durante o governo do presidente Luiz Inácio Lula da Silva, a formação específica na área de Educação Especial vem e continua sendo historicamente concebida no modelo de formação continuada (REBELO, 2016).

Nesse sentido, as políticas públicas de formação docente para atender pessoas com deficiência nas instituições de ensino foram sendo desenhadas para qualificar os professores em serviço, através da formação continuada e usando principalmente a Educação à Distância (EAD). A lei ㄲo 10.172/2001, que aprovou o Plano Nacional de Educação para o decênio 2001-2011, e a lei no 13.005/2014, que aprova o Plano Nacional de Educação entre os anos de 2014 e 2024, quando referem à Educação Especial afirmam:

Generalizar, em cinco anos, como parte dos programas de formação em serviço, a oferta de cursos sobre o atendimento básico a educandos especiais, para os professores em exercício na educação infantil e no ensino fundamental, utilizando inclusive a TV Escola e outros programas de educação à distância (BRASIL, 2001, Lei № 10.172/2001).

Implantar, ao longo deste PNE, salas de recursos multifuncionais e fomentar a formação continuada de professores e professoras para o atendimento educacional especializado nas escolas urbanas, do campo, indígenas e de comunidades quilombolas (BRASIL, 2014, Lei oㅜ 13.005/2014)

Esse modelo de formação continuada no formato EAD vem sendo amplamente adotado pelo governo brasileiro desde 2003, quando a Secretaria de Educação Especial do Ministério da Educação (SEESP/MEC), em parceria com a Secretaria de Educação à Distância passaram a oferecer o Curso de Formação Continuada à Distância de Professores para o Atendimento Educacional Especializado, compondo as ações do Programa de Educação Inclusiva: Direito à Diversidade (GARCIA, 2013; SOUZA BRIDI, 2011).

No ano de 2009 foi lançado o Programa de Formação Continuada de Professores na Educação Especial com a finalidade de apoiar a formação dos docentes para atuar nas Salas de Recursos Multifuncionais e em classes comuns do ensino regular. Essa ação foi desenvolvida com a colaboração das instituições públicas de educação superior. Foram ofertados cursos de aperfeiçoamento e especialização lato sensu, na modalidade EAD, através da Universidade Aberta do Brasil. A estes programas, deve-se acrescentar outras ações de formação continuada, como os programas de interiorização de LIBRAS e Braille, 
http://dx.doi.org/10.5902/1984686X39223

o projeto de Informática na Educação Especial, entre outros (KASSAR, 2014; GARCIA, 2013).

Todos esses cursos ofertados buscaram sanar a ausência de formação dos professores para lidar com os alunos com deficiência que ingressaram no ensino regular e para os quais os professores, em sua maioria, não estavam preparados. Porém, alguns problemas foram observados: falhas na articulação entre as esferas federal, estadual e municipal nas ofertas e administração dos cursos; problemas referentes aos conteúdos desenvolvidos durante as formações que não dialogavam com a prática cotidiana dos docentes, além das condições precárias em que, às vezes, esses cursos eram ofertados (KASSAR, 2014; GREGUOL; GOBBI; CARRARO, 2013)

Souza Bridi (2011) analisa que, desde os anos 2000, o Brasil adotou medidas para a formação de professores condizentes com as recomendações de organismos internacionais, as quais visam atender às necessidades de formação de professores, sem, no entanto, elevar os custos do sistema educacional. Por conta disso, a modalidade EAD foi priorizada, juntamente com uma alteração na concepção e no caráter do trabalho docente.

Esse discurso de profissionalização docente, no Brasil, encontra-se fortemente descontextualizado do âmbito educativo e dos atores educacionais. Elementos como a racionalização de recursos e a privatização fundamentam um processo de controle externo da profissão. Esse contexto tem levado, contraditoriamente, a uma desprofissionalização docente impondo a essa categoria profissional precárias condições de trabalho e desvalorização social (AKKARI, 2011).

Outras políticas públicas relacionadas à inclusão de alunos com deficiência pautaram a formação de professores para atender a esse público a partir da introdução de conteúdos inerentes às pessoas com deficiência nos currículos dos cursos de licenciatura e Pedagogia. A exemplo disso, observa-se a Portaria no 1.793/1994, do Ministério da Educação que recomendava a inclusão da disciplina "aspectos ético-político educacionais da normalização e integração da pessoa portadora de necessidades especiais" (BRASIL, 1994).

Outros dispositivos normativos com a mesma finalidade foram criados ao longo dos anos: 
http://dx.doi.org/10.5902/1984686X39223

O sistema educacional federal e os sistemas educacionais estaduais, municipais e do Distrito Federal devem garantir a inclusão nos cursos de formação de Educação Especial e de Magistério, em seus níveis médio e superior, do ensino da Língua Brasileira de Sinais - Libras, como parte integrante dos Parâmetros Curriculares Nacionais - PCNs, conforme legislação vigente. (BRASIL, 2002, Lei no 10.436/2002)

A Libras deve ser inserida como disciplina curricular obrigatória nos cursos de formação de professores para o exercício do magistério, em nível médio e superior de instituições de ensino, públicas e privadas, do sistema federal de ensino e dos sistemas de ensino dos Estados, do Distrito Federal e dos Municípios. (BRASIL, 2005, Decreto № 5.626/2005)

O Estado deve assegurar a formação e disponibilização de professores para o atendimento educacional especializado, de tradutores e intérpretes de LIBRAS, de guias intérpretes e de profissionais de apoio e a inclusão em conteúdos curriculares, em cursos de nível superior e de educação profissional técnica e tecnológica, de temas relacionados à pessoa com deficiência nos respectivos campos de conhecimento. (BRASIL, 2015, Lei no 13.146/2015).

Em se tratando de formação docente, a aprovação de Diretrizes Curriculares Nacionais para a Formação de Professores foi um passo importante para uma melhor qualificação na formação inicial desses profissionais. Esse fato também consolidou a inclusão de conteúdos relacionados às pessoas com deficiência nas Licenciaturas e na Pedagogia. A diretriz do ano de 2002, Resolução ํo1/2002, do Conselho Nacional de Educação, postula que os cursos de formação de professores devem organizar seus currículos de modo que a atividade docente esteja orientada para o acolhimento e o trato da diversidade e que propiciem a inserção no debate contemporâneo mais amplo incluindo conhecimentos sobre as especificidades dos alunos com deficiência (CNE, 2002).

Com esse entendimento mais consolidado, as novas diretrizes curriculares nacionais para formação inicial em nível superior dos cursos de licenciatura, cursos de formação pedagógica para graduados e cursos de segunda licenciatura, aprovada pela resolução no 2/2015, do Conselho Nacional de Educação, possui em todo seu escopo uma preocupação em relação à formação de professores que sejam comprometidos com a construção de uma sociedade inclusiva e que promova a emancipação dos indivíduos e grupos sociais. Também está atenta ao reconhecimento e à valorização da diversidade e, portanto, é contrária a toda forma de discriminação; há, também, menção ao fortalecimento da LIBRAS e de conteúdos relacionados à inclusão e Educação Especial (CNE, 2015). 
http://dx.doi.org/10.5902/1984686X39223

Apesar da obrigatoriedade de inserção dos conteúdos inerentes à inclusão de pessoas com deficiência nos cursos de formação de professores, não há necessariamente a garantia que os cursos venham qualificando os futuros professores para o atendimento do público-alvo da Educação Especial na Educação Básica (GARCIA, 2013; MARTINS, 2012).

Uma política pública específica para a formação inicial de professores voltada para o atendimento de pessoas com deficiência foi a criação nos anos 2000 de licenciaturas em Educação Especial em algumas universidades da rede pública e privada. Os dados mais atualizados existentes no sistema e-mec, plataforma em que disponibiliza dados referentes ao credenciamento e ao recredenciamento, autorização e reconhecimento das Instituições de educação superior, contabilizam a existência de 38 cursos de licenciatura em Educação Especial cadastrados no Ministério da Educação, sendo que apenas 21 estão em funcionamento, tendo a oferta majoritária de vagas na modalidade EAD e em instituições particulares (BRASIL, 2019c).

Oliveira e Mendes (2017) analisando o currículo dos cursos de licenciatura em Educação Especial indicam que a falta de uma diretriz curricular nacional para esses cursos proporciona características diversas aos mesmos. Chama a atenção a constatação, dessas mesmas autoras, de que alguns cursos da iniciativa privada funcionavam em sistema de convênio com o Plano Nacional de Formação de Professores da Educação Básica (Parfor) ou até com programas específicos de formação das Secretarias Estaduais de Educação. De forma categórica, pode-se afirmar que o número de cursos ainda é insuficiente para a demanda educacional brasileira.

Compete destacar que a Resolução no 2/2001, do Conselho Nacional de Educação, que instituiu as Diretrizes Nacionais para a Educação Especial na Educação Básica estabeleceu:

Art. $8^{\circ}$ As escolas da rede regular de ensino devem prever e prover na organização de suas classes comuns: I - professores das classes comuns e da educação especial capacitados e especializados, respectivamente, para 0 atendimento às necessidades educacionais dos alunos (CNE, 2001, Resolução no 2/2001)

Art. 18, § $3^{\circ}$ Os professores especializados em educação especial deverão comprovar:

I - Formação em cursos de licenciatura em educação especial ou em uma de suas áreas, preferencialmente de modo concomitante e associado à licenciatura para educação infantil ou para os anos iniciais do ensino fundamental; 
http://dx.doi.org/10.5902/1984686X39223

II - Complementação de estudos ou pós-graduação em áreas específicas da educação especial, posterior à licenciatura nas diferentes áreas de conhecimento, para atuação nos anos finais do ensino fundamental e no ensino médio;

$\S 4^{\circ}$ Aos professores que já estão exercendo o magistério devem ser oferecidas oportunidades de formação continuada, inclusive em nível de especialização, pelas instâncias educacionais da União, dos Estados, do

Distrito Federal e dos Municípios. (CNE, 2001, Resolução oㅡㄹ2/2001)

Essas medidas fazem crescer a exigência do mercado na procura de profissionais especialistas qualificados, especificadamente em Educação Especial, para atender a essa nova demanda de mão-de-obra. Akkari (2011) sugere que as pressões econômicas sobre os professores refletem na divisão do trabalho entre os atores da educação, interferindo inclusive nas condições dos contratos e salários dos docentes e na natureza de suas atividades laborais cotidianas.

\section{Considerações finais}

As políticas públicas de inclusão escolar na área de Educação Especial provocaram profundas modificações no sistema de ensino brasileiro, principalmente, a partir dos anos 2000, com o ingresso significativo de estudantes com deficiência nas instituições escolares do ensino regular. Todo esse cenário ocasionou, concomitantemente, transformações no trabalho docente e exigiram políticas de formação que qualificassem os professores para lidar com essa nova realidade e garantir a qualidade do processo de ensino-aprendizagem dos alunos.

Porém, o que se constata ao analisar as políticas públicas de inclusão de alunos com deficiência e formação de professores para atendê-los na Educação Básica é um descompasso entre a reforma que proporcionou o acesso dos alunos e a preocupação em qualificar os docentes para o trabalho com os mesmos. A formação docente, muitas vezes, nem é citada nas políticas que tratam de inclusão escolar de pessoas com deficiência, e quando são, estas aparecem secundarizadas e generalizadas, o que dificulta a compreensão da política de formação adotada no país.

Algumas ações levam a crer que o Brasil, seguindo o padrão de internacionalização das políticas educacionais, procurou formar seus professores para atender ao públicoalvo da Educação Especial, através de um modelo de baixo custo baseado, principalmente, na formação continuada e em serviço, ofertada na modalidade à distância. As iniciativas em relação à formação inicial apenas figuram no campo da inserção de conteúdos relacionados à inclusão nos cursos superiores de formação de professores, o 
http://dx.doi.org/10.5902/1984686X39223

que vem se mostrando insuficiente para preparar os futuros profissionais para a realidade que encontrarão nas escolas.

Muito obstante aos limites das políticas vigentes, a conjuntura atual suscita dúvidas sobre a continuidade da Política Nacional da Educação Especial em uma perspectiva inclusiva, considerando o movimento revisionista iniciado em 2017, após o impeachment da presidente Dilma Rousseff. A proposta apresentada pelo Ministério da Educação, do Governo Temer e encampada pelo Governo Bolsonaro, tem sido alvo de severas críticas por várias entidades, que apontam retrocessos no que diz respeito à perspectiva inclusiva, bem como a ampliação do público-alvo da Educação Especial, fortalecimento de instituições especializadas e a volta de modelos paralelos e fragmentados entre Educação Especial e ensino regular. Consequentemente, corre-se o risco de retrocessos no modelo educativo da pessoa com deficiência e o retorno à institucionalização.

Todo esse quadro pode ser agravado pelos recentes cortes nos recursos destinados à educação realizados pelo governo do presidente Jair Bolsonaro, em especial os alocados para as Universidades Públicas Federais, que comprometem a formação de professores, uma vez que essas instituições, historicamente, são as maiores e mais importantes propulsoras da formação docente, inicial e/ou continuada, no Brasil.

Por fim, o modelo fragmentado de inclusão em que a inserção dos alunos com deficiência no sistema de ensino, por vezes, é pensada isoladamente e distanciada da formação dos profissionais da educação, fomenta sistemas educacionais de baixa qualidade e que continuam fadados à exclusão e ao fracasso no processo de ensinoaprendizagem de alunos que há muito tempo clamam por uma política pública educacional que oportunize condições apropriadas para seu pleno desenvolvimento.

\section{Referências}

AKKARI, Abdeljalil. Internacionalização das políticas educacionais: transformações e desafios. Petrópolis: Vozes, 2011. 143p.

AMARAL, Marcelo Parreira do. Política pública educacional e sua dimensão internacional: abordagens teóricas. Educ. Pesqui. São Paulo, v. 36, n. spe, p. 39-54, abr. 2010.

Disponível em: http://www.scielo.br/scielo.php?script=sci_arttext\&pid=S1517-

97022010000400004\&Ing=pt\&nrm=iso . Acesso em: 04 jul. 2019. http://dx.doi.org/10.1590/S1517-97022010000400004.

BALL, Stephen. J. \& MAINARDES, Jefferson (org). Políticas Educacionais: questões e dilema. São Paulo: Cortez, 2011. 
BANCO MUNDIAL. Human Development Network. Education sector strategy. World Bank. Washington, D.C. 1999. Disponível em: http://documents.worldbank.org/curated/pt/469761468150873366/Estrategia-sectorial-deeducacion. Acesso em: 20 dez. 2018.

BARDIN, Laurence. Análise de conteúdo. Lisboa - Portugal: edições 70, 2004. 223p.

BRASIL. Congresso Nacional. Decreto Legislativo no 186/2008. Aprova o texto da Convenção sobre os Direitos das Pessoas com Deficiência e de seu Protocolo Facultativo, assinados em Nova lorque, em 30 de março de 2007. Brasília, DF, 2008a. Disponível em: http://www.planalto.gov.br/ccivil_03/CONGRESSO/DLG/DLG-1862008.htm. Acesso em: 28 jan. 2019.

BRASIL. Congresso Nacional. Decreto no 6.571, de 17 de setembro de 2008. Dispõe sobre o atendimento educacional especializado, regulamenta o parágrafo único do art. 60 da Lei no 9.394, de 20 de dezembro de 1996, e acrescenta dispositivo ao Decreto no 6.253, de 13 de novembro de 2007. Brasília, DF. 2008b. Disponível em:

http://www.planalto.gov.br/ccivil_03/_ato2007-2010/2008/decreto/d6571.htm. Acesso em: 28 jan. 2019.

BRASIL. Constituição [de 1988] da República Federativa do Brasil. Diário Oficial da União, Brasília, DF, 5 out. 1988.

BRASIL. Ministério da Educação. Sistema e-MEC: instituições de educação superior e cursos cadastrados. Brasília, DF, 2019c. Disponível em: http://emec.mec.gov.br/. Acesso em: 14 março 2019.

BRASIL. Ministro da Educação, Ministro de Desenvolvimento Social e de Combate à Fome, Ministro da Saúde e Secretária Especial Dos Direitos Humanos. Portaria normativa interministerial no- 18, de 24 de abril de 2007. Brasília, DF, 2007a. Disponível em: http://portal.mec.gov.br/arquivos/pdf/bpc.pdf. Acesso em: 28 jan. 2019.

BRASIL. Ministro de Estado da Educação e do Desporto. Portaria n.ำ 1.793, de dezembro de 1994. Brasília, DF, 1994. Disponível em:

http://portal.mec.gov.br/seesp/arquivos/pdf/port1793.pdf. Acesso em: 28 jan. 2019.

BRASIL. Presidência da República. Decreto n 3.956, de 08 de outubro de 2001. Promulga a Convenção Interamericana para a Eliminação de Todas as Formas de Discriminação contra as Pessoas Portadoras de Deficiência. Brasília, DF, 2001a. Disponível em: http://www.planalto.gov.br/ccivil_03/decreto/2001/D3956.htm. Acesso em: 28 jan. 2019.

BRASIL. Presidência da República. Decreto no 5.626, de 22 de dezembro de 2005. Regulamenta a Lei no 10.436, de 24 de abril de 2002, que dispõe sobre a Língua Brasileira de Sinais - Libras, e o art. 18 da Lei no 10.098, de 19 de dezembro de 2000. Brasília, DF, 2005. Disponível em: https://www2.camara.leg.br/legin/fed/decret/2005/decreto-5626-22-dezembro-2005539842-publicacaooriginal-39399-pe.html. Acesso em: 28 jan. 2019. 
BRASIL. Presidência da República. Decreto n 6.094, de 24 de abril de 2007. Dispõe sobre a implementação do Plano de Metas Compromisso Todos pela Educação (...). 2007. Brasília, DF. 2007a. Disponível em: http://www.planalto.gov.br/ccivil_03/_ato20072010/2007/decreto/d6094.htm. Acesso em: 28 jan. 2019.

BRASIL. Presidência da República. Decreto no 6.949 de 25 de agosto de 2009.

Promulga a Convenção Internacional sobre os Direitos das Pessoas com Deficiência e seu Protocolo Facultativo, assinados em Nova York, em 30 de março de 2007. Brasília, DF. 2009b. Disponível em: http://www.planalto.gov.br/ccivil_03/_ato20072010/2009/decreto/d6949.htm. Acesso em: 28 jan. 2019.

BRASIL. Presidência da República. Decreto no 7.611, de 17 de novembro de 2011. Dispõe sobre a educação especial, o atendimento educacional especializado e dá outras providências. Brasília, DF. 2011. Disponível em:

http://www.planalto.gov.br/ccivil_03/_Ato2011-2014/2011/Decreto/D7611.htm. Acesso em: 28 jan. 2019.

BRASIL. Presidência da República. Decreto no 9.465, de 2 de janeiro de 2019. Aprova a Estrutura Regimental e o Quadro Demonstrativo dos Cargos em Comissão e das Funções de Confiança do Ministério da Educação, remaneja cargos em comissão e funções de confiança e transforma cargos em comissão do Grupo-Direção e Assessoramento Superiores - DAS e Funções Comissionadas do Poder Executivo - FCPE. Brasília, DF, 2019a. Disponível em: http://www.in.gov.br/materia/-

/asset_publisher/Kujrw0TZC2Mb/content/id/57633286. Acesso em: 28 jan. 2019.

BRASIL. Presidência da República. Decreto no 9.741 de 29 de março de 2019. Altera o Decreto n o 9.711, de 15 de fevereiro de 2019, que dispõe sobre a programação orçamentária e financeira, estabelece o cronograma mensal de desembolso do Poder Executivo federal para o exercício de 2019 e dá outras providências. Brasília, DF, 2019b. Disponível em: http://www.planalto.gov.br/ccivil_03/_ato20192022/2019/decreto/D9741.htm. Acesso em: 30 mai. 2019.

BRASIL. Presidência da República. Lei no 10.098 de 19 de dezembro de 2000.

Estabelece normas gerais e critérios básicos para a promoção da acessibilidade das pessoas portadoras de deficiência ou com mobilidade reduzida, e dá outras providências. 2000. Brasília, DF, 2000. Disponível em:

http://www.planalto.gov.br/ccivil_03/leis/l10098.htm. Acesso em: 28 jan. 2019.

BRASIL. Presidência da República. Lei no 10.172, de 9 de janeiro de 2001. Aprova o Plano Nacional de Educação e dá outras providências. Brasília, DF, 2001b. Disponível em: http://www.planalto.gov.br/ccivil_03/leis/leis_2001//10172.htm. Acesso em: 28 jan. 2019.

BRASIL. Presidência da República. Lei no 10.436, de 24 de abril de 2002. Dispõe sobre a Língua Brasileira de Sinais - Libras e dá outras providências. Brasília, DF, 2002. Disponível em: http://www.planalto.gov.br/ccivil_03/leis/2002//10436.htm. Acesso em: 28 jan. 2019. 
BRASIL. Presidência da República. Lei no 13.005, de 25 de junho de 2014. Aprova o Plano Nacional de Educação - PNE e dá outras providências. 2014. Brasília, DF, 2014. Disponível em: http://www.planalto.gov.br/ccivil_03/_ato2011-2014/2014/lei/13005.htm. Acesso em: 28 jan. 2019.

BRASIL. Presidência da República. Lei no 13.146 de 06 de julho de 2015. Institui a Lei Brasileira de Inclusão da Pessoa com Deficiência (Estatuto da Pessoa com Deficiência). Brasília, DF, 2015. Disponível em: http://www.planalto.gov.br/ccivil_03/leis/l10098.htm. Acesso em: 28 jan. 2019.

CAIADO, Katia Regina Moreno et al. DEFICIÊNCIA E DESIGUALDADE SOCIAL: O RECENTE CAMINHO PARA A ESCOLA. Cad. CEDES, Campinas, v. 34, n. 93, p. 241260, maio 2014. Disponível em:

http://www.scielo.br/scielo.php?script=sci_arttext\&pid=S0101$32622014000200241 \&$ Ing=pt\&nrm=iso. Acesso em: 04 jul. 2019. http://dx.doi.org/10.1590/S0101-32622014000200007.

CARVALHO, Guilherme Augusto Batista. A FORMAÇÃO DA AGENDA DE POLÍTICAS PÚBLICAS NO PRESIDENCIALISMO DE COALIZÃO. Olhares Plurais, Maceió-AL, v. 1, n. 16, p. 170-179, mar. 2017. ISSN 2176-9249. Disponível em:

http://revista.seune.edu.br/index.php/op/article/view/239/206 . Acesso em: 04 jul. 2019.

CONGRESSO INTERNACIONAL SOCIEDADE INCLUSIVA. Declaração internacional de Montreal sobre inclusão. Montreal, 2001. Disponível em:

http://portal.mec.gov.br/seesp/arquivos/pdf/dec_inclu.pdf. Acesso em: 30 jan. 2019.

CONSELHO NACIONAL DE EDUCAÇÃO (CNE). Ministério da Educação. Resolução cne/ceb no 2, de 11 de setembro de 2001. Institui Diretrizes Nacionais para a Educação Especial na Educação Básica. Brasília, DF, 2001. Disponível em: http://portal.mec.gov.br/cne/arquivos/pdf/CEB0201.pdf. Acesso em: 28 jan. 2019.

CONSELHO NACIONAL DE EDUCAÇÃO (CNE). Ministério da Educação. Resolução cne/cp nำ1, de 18 de fevereiro de 2002. Institui Diretrizes Curriculares Nacionais para a Formação de Professores da Educação Básica, em nível superior, curso de licenciatura, de graduação plena. Brasília, DF, 2002. Disponível em:

http://portal.mec.gov.br/cne/arquivos/pdf/rcp01_02.pdf. Acesso em: 28 jan. 2019.

CONSELHO NACIONAL DE EDUCAÇÃO (CNE). Ministério da Educação. Resolução cne/cp no2, de 1 de julho de 2015. Define as Diretrizes Curriculares Nacionais para a formação inicial em nível superior (cursos de licenciatura, cursos de formação pedagógica para graduados e cursos de segunda licenciatura) e para a formação continuada. Brasília, DF, 2015. Disponível em:

http://portal.mec.gov.br/index.php?option=com_docman\&view=download\&alias=98191res-cp-02-2015\&category_slug=outubro-2018-pdf-1\&ltemid=30192. Acesso em: 28 jan. 2019.

CUNHA, Monica Isabel Carleti. Programa BPC na escola: dilemas e perspectivas no campo dos direitos sociais. Dissertação (Mestrado em Educação). Universidade Federal do Espírito Santo, Centro de Educação. Santa Catarina, 2015. 140p. 
FRANCA, Marileide Gonçalves; PRIETO, Rosângela Gavioli. Financiamento da Educação Especial no Município de Vitória: desafios à gestão. Educ. rev., Curitiba, v. 34, n. 71, p. 279-296, out. 2018. Disponível em:

http://www.scielo.br/scielo.php?script=sci_arttext\&pid=S0104-

$40602018000500279 \&$ Ing=pt\&nrm=iso. Acesso em: 04 jul. 2019.

http://dx.doi.org/10.1590/0104-4060.59229.

FRANCA, Marileide Gonçalves. O financiamento da educação especial no âmbito dos fundos da educação básica: Fundef e Fundeb. Educ. rev. Curitiba, n. 58, p. 271-286, dez. 2015. Disponível em: http://www.scielo.br/scielo.php?script=sci_arttext\&pid=S0104$40602015000400271 \&$ lng=pt\&nrm=iso. Acesso em: 04 jul. 2019.

http://dx.doi.org/10.1590/0104-4060.42415.

FUNDO NACIONAL DE DESENVOLVIMENTO DA EDUCAÇÃO (FNDE). Ministério da Educação. Resolução/CD/FNDE no 26, de 15 de junho de 2007. Estabelece as orientações e diretrizes para assistência financeira suplementar a projetos educacionais da Educação Especial, no exercício de 2007. Brasília, DF, 2007. Disponível em: https://www.fnde.gov.br/acesso-a-informacao/institucional/legislacao/item/3147resolu\%C3\%A7\%C3\%A3o-cd-fnde-n\%C2\%BA-26-de-15-de-junho-de-2007. Acesso em: 28 jan 2019.

FUNDO NACIONAL DE DESENVOLVIMENTO DA EDUCAÇÃO (FNDE). Ministério da Educação. Resolução/CD/FNDE no 20, de 19 de outubro de 2018. Dispõe sobre a destinação de recursos financeiros, nos moldes operacionais e regulamentares do Programa Dinheiro Direto na Escola (...) em conformidade com o Programa Escola Acessível. Brasília, DF, 2018. Disponível em: https://www.fnde.gov.br/acesso-ainformacao/institucional/legislacao/item/3147-resolu\%C3\%A7\%C3\%A3o-cd-fnden\%C2\%BA-26-de-15-de-junho-de-2007. Acesso em: 28 jan 2019.

GARCIA, Rosalba Maria Cardoso. Política de educação especial na perspectiva inclusiva e a formação docente no Brasil. Rev. Bras. Educ., Rio de Janeiro, v. 18, n. 52, p. 101119, mar. 2013. Disponível em:

http://www.scielo.br/scielo.php?script=sci_arttext\&pid=S1413-

$24782013000100007 \&$ Ing=pt\&nrm=iso. Acesso em: 04 jul. 2019.

http://dx.doi.org/10.1590/S1413-24782013000100007.

GREGUOL, Márcia; GOBBI, Erica; CARRARO, Attilio. Formação de professores para a educação especial: uma discussão sobre os modelos brasileiro e italiano. Rev. bras. educ. espec. Marília, v. 19, n. 3, p. 307-324, set. 2013. Disponível em:

http://www.scielo.br/scielo.php?script=sci_arttext\&pid=S1413-

$65382013000300002 \&$ Ing=pt\&nrm=iso. Acesso em: 04 jul. 2019.

http://dx.doi.org/10.1590/S1413-65382013000300002.

INSTITUTO NACIONAL DE ESTUDOS E PESQUISAS EDUCACIONAIS ANÍSIO TEIXEIRA (INEP). Ministério da Educação. Sinopse Estatística da Educação Básica do ano 2000. Brasília, DF, 2001. Disponível em: http://portal.inep.gov.br/web/guest/sinopsesestatisticas. Acesso em: 11 mar. 2019. 
INSTITUTO NACIONAL DE ESTUDOS E PESQUISAS EDUCACIONAIS ANÍSIO TEIXEIRA (INEP). Ministério da Educação. Sinopse Estatística da Educação Básica do ano 2018. Brasília, DF, 2019. Disponível em: http://portal.inep.gov.br/web/guest/sinopsesestatisticas. Acesso em: 11 mar. 2019.

KASSAR, Mônica de Carvalho Magalhães. A FORMAÇÃO DE PROFESSORES PARA A EDUCAÇÃO INCLUSIVA E OS POSSÍVEIS IMPACTOS NA ESCOLARIZAÇÃO DE ALUNOS COM DEFICIÊNCIAS. Cad. CEDES, Campinas, v. 34, n. 93, p. 207224, maio 2014. Disponível em: http://www.scielo.br/scielo.php?script=sci_arttext\&pid=S0101$32622014000200207 \&$ Ing=pt\&nrm=iso. Acesso em: 04 jul. 2019. http://dx.doi.org/10.1590/S0101-32622014000200005.

KUHN, Cleuza. Educação inclusiva: das ações institucionais à formação inicial de professores na UFPR. Dissertação de Mestrado, Setor de Educação, Universidade Federal do Paraná, Curitiba, PR, 2011. 105p.

LAPLANE, Adriana Lia Friszman. O que os dados do censo escolar revelam sobre as barreiras à inclusão? Educação e Fronteiras, Dourados, v. 5, n. 14, p. 7-20, mar. 2016. ISSN 2237-258X. Disponível em: http://ojs.ufgd.edu.br/index.php/educacao/article/view/3762. Acesso em: 04 jul. 2019.

LIBÂNIO, José Carlos; OLIVEIRA, João Ferreira; TOSCHI, Mirza Seabra. Educação Escolar: políticas, estruturas e organização. 10ª ed. São Paulo: Cortez, 2012.

MANTOAN, Maria Teresa Eglér (org). Em Defesa da política nacional de educação especial na perspectiva da educação inclusiva: análise e manifestação sobre a proposta do MEC de reformar a política nacional de educação especial na perspectiva da educação inclusiva. LEPED. FE/UNICAMP. 2018. Disponível em:

https://inclusaoja.com.br/2018/03/21/manifesto-da-sociedade-civil-em-relacao-a-basenacional-comum-curricular-bncc/. Acesso em: 26 mar. 2019

MARTINS, Lúcia de Araújo Ramos. Reflexões sobre a formação de professores com vistas à educação inclusiva. In: MIRANDA, Theresinha Guimarães; GALVÃO-FILHO, Teófilo Alves. (Org.). O professor e a educação inclusiva: formação, práticas e lugares. Salvador: EDUFBA. 2012. p. 25- 38

MENDES, Enicéia Gonçalves. (2019). A política de educação inclusiva e o futuro das instituições especializadas no Brasil. Arquivos Analíticos de Políticas Educativas, v. 27, n. 22, 18 de março 2019. Disponível em: https://epaa.asu.edu/ojs/article/view/3167/2217. Acesso em: 30 de abr. 2019. http://dx.doi.org/10.14507/epaa.27.3167

MOTA JUNIOR, William Pessoa da; MAUES, Olgaíses Cabral. O Banco Mundial e as Políticas Educacionais Brasileiras. Educ. Real. Porto Alegre, v. 39, n. 4, p. 1137-1152, dez. 2014. Disponível em: http://www.scielo.br/scielo.php?script=sci_arttext\&pid=S217562362014000400010\&lng=pt\&nrm=iso. Acesso em: 04 jul. 2019. http://dx.doi.org/10.1590/S2175-62362014000400010. 
OLIVEIRA, Dalila Andrade. A política educacional brasileira: entre a eficiência e a inclusão democrática. Educação e Filosofia Uberlândia, v. 28, n. especial, 225-243. 2014. Disponível em: http://www.seer.ufu.br/index.php/EducacaoFilosofia/article/view/24611. Acesso em: 29 jan 2019. doi: https://doi.org/10.14393/REVEDFIL.issn.01026801.v28nEspeciala2014-p225a243

OLIVEIRA, Patricia Santos de; MENDES, Enicéia Gonçalves. Análise do projeto pedagógico e da grade curricular dos cursos de licenciatura em educação especial. Educ. Pesqui. São Paulo, v. 43, n. 1, p. 264-279, mar. 2017. Disponível em: http://www.scielo.br/scielo.php?script=sci arttext\&pid=S151797022017000100264\&lng=pt\&nrm=iso. Acesso em: 04 jul. 2019. Epub 07-Jul-2016. http://dx.doi.org/10.1590/s1517-9702201605145723.

\section{ORGANIZAÇÃO DAS NAÇÕES UNIDAS (ONU). Convenção sobre os Direitos das} Pessoas com Deficiência. Assembleia Geral das Nações Unidas, 6 de dezembro de 2006. 2017. Disponível em:

http://portal.mec.gov.br/index.php?option=com_docman\&view=download\&alias=424cartilha-c\&category_slug=documentos-pdf\&Itemid=30192. Acesso em: 28 jan 2019

PANSINI, Flávia. Salas de recursos multifuncionais no brasil: para quê e para quem? Tese (Doutorado em Educação). Universidade Federal do Amazonas, UFAM. Manaus, 2018. 206p.

REBELO, Andressa Santos. Política de inclusão escolar no Brasil (2003-2010). Journal of Research in Special Educational Needs. v. 16. n. 1 p. 851-854. 2016. Disponível em: https://onlinelibrary.wiley.com/doi/epdf/10.1111/1471-3802.12341. Acesso em: 26 mar. 2019 doi: $10.1111 / 1471-3802.12341$

ROCHA, Carlos Vasconcelos. Ideias e formação de agenda de uma reforma educacional. Ensaio: Avaliação e Políticas Públicas em Educação, [S.I.], v. 19, n. 70, p. 191-218, jan. 2011. ISSN 1809-4465. Disponível em:

http://revistas.cesgranrio.org.br/index.php/ensaio/article/view/459. Acesso em: 04 jul. 2019.

SÁ-SILVA, Jackson Ronie; ALMEIDA, Cristóvão Domingos de; GUINDANI, Joel Felipe. Pesquisa documental: pistas teóricas e metodológicas. Revista Brasileira de História \& Ciências Sociais, v. 1, n.1, p. 01-14. 2009. Disponível em: https://www.rbhcs.com/rbhcs/article/view/6. Acesso em: 04 jul. 2019.

SAVIANI, Dermeval. Formação de professores: aspectos históricos e teóricos do problema no contexto brasileiro. Rev. Bras. Educ. Rio de Janeiro, v. 14, n. 40, p. 143155, abr. 2009. Disponível em: http://www.scielo.br/scielo.php?script=sci_arttext\&pid=S1413$24782009000100012 \&$ lng=pt\&nrm=iso. Acesso em: 04 jul. 2019. http://dx.doi.org/10.1590/S1413-24782009000100012.

SILVA, Iraci Balbina Gonçalves. O BANCO MUNDIAL E AS POLÍTICAS EDUCACIONAIS. Ciclo Revista, [S.I.], set. 2016. ISSN 2526-8082. Disponível em: https://www.ifgoiano.edu.br/periodicos/index.php/ciclo/article/view/225. Acesso em: 04 jul. 
2019.

SOUZA BRIDI, Fabiane Romano de. Formação continuada em educação especial: o atendimento educacional especializado. Poiésis - Revista do Programa de PósGraduação em Educação, [S.I.], v. 4, n. 7, p. 187-199, jun. 2011. ISSN 2179-2534. Disponível em: http://www.portaldeperiodicos.unisul.br/index.php/Poiesis/article/view/655. Acesso em: 04 jul. 2019. doi: http://dx.doi.org/10.19177/prppge.v4e72011187-199.

SOUZA, Celina. Políticas públicas: uma revisão da literatura. Sociologias, Porto Alegre, n. 16, p. 20-45, dez. 2006. Disponível em:

http://www.scielo.br/scielo.php?script=sci_arttext\&pid=S1517-

$45222006000200003 \&$ Ing=pt\&nrm=iso. Acesso em: 04 jul. 2019.

http://dx.doi.org/10.1590/S1517-45222006000200003.

TARDIF, Maurice. Saberes docentes e formação profissional. $17^{a}$ ed. Petrópolis, RJ: Vozes. 2014.

UNESCO - United Nations Educational, Scientific and Cultural Organization. The

Salamanca Statement and Framework for Action on Special Needs

Education. Salamanca. 1994. Disponível em:

http://www.unesco.org/education/pdf/SALAMA_E.PDF. Acesso em: 23 maio 2015.

\section{Correspondência}

Bruno Cleiton Macedo do Carmo - Universidade Federal de Alagoas, Campus Arapiraca, Av. Manoel Severino Barbosa, s/n, Rodovia AL 115, Arapiraca, Alagoas, Brasil.

CEP: 57309-005

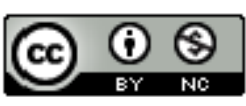

This work is licensed under a Creative Commons Attribution-NonCommercial 4.0 International (CC BY-NC 4.0) 